\title{
Isolation and Characterization of Malasezzia Species from Dandruff Samples and Determination of its Sensitivity Towards Antifungal Agents
}

\author{
Kohinur Begum, Farjahan Nur and Mashmum Shababa Shahid \\ Department of Pharmacy, ASA University Bangladesh, ASA Tower, Shyamoli, Dhaka-1207, Bangladesh
}

(Received: January 15, 2019; Accepted: February 17, 2019; Published: July 22, 2019)

\begin{abstract}
Dandruff is a perennial skin condition manifesting as inflammation and physiologic scaling on the scalp. Malassezia species are the part of the skin microflora of humans and the etiological agents of dandruff. Malassezia comprises of lipophilic and non-lipophilic yeasts. At present topical azoles are used for the treatment of dandruff. This study was conducted to isolate and identify the Malassezia spp. from dandruff samples and to determine their responsiveness towards antifungal agents such as fluconazole, ketoconazole, miconazole and nystatin. Malassezia spp. was isolated using selective media and identified by biochemical tests and microscopic examination. Antifungal activities were assessed by the Kirby Bauer method using well diffusion technique. Total fifteen Malassezia spp. including $M$. furfur, M. pachydermatis, M. sympodialis and M. globosa were identified from twenty five dandruff samples. Among them, M. furfur was most prevalent (66.67\%) followed by M. pachydermatis (13.33\%), M. sympodialis (13.33\%) and M. globosa (6.67\%). All strains were sensitive to the antifungal agents but to different extent. Fluconazole and ketoconazole proved to be the most effective agents against these microorganisms.
\end{abstract}

Key words: Dandruff, Malassezia species, antifungal agents.

\section{Introduction}

Dandruff is an inflammatory skin condition with a high recurrence rate, seen in almost half of the population of the world (Elewski, 2005; Hay, 2011). It manifests as white to yellowish flaky scales mainly on the scalp which can cause irritation and be a cosmetic concern (Rudramurthy et al., 2014). Inflammation and scaling beyond the scalp, extending to nasolabial folds, eyebrows, behind the ears and on the chest (Hay and Graham-Brown, 1997) where the sebaceous glands are mostly present, is referred to as seborrheic dermatitis. Malassezia spp. are commensals on human skin which are mostly lipophilic in nature and can thrive by metabolizing the fatty compounds in sebum. In the late 19th century, the principal evidence which established a connection between Malassezia spp. and dandruff was their increased presence by 1.5-2 times the normal level on the skin of people suffering from dandruff (Hay, 2011; Ranganathan and Mukhopadhyay, 2010). Guillot and his colleagues (1996) reported that $M$. globosa, M. restricta, $M$. obtusa, M. sloofiae, M. sympodialis, M. furfur and $M$. pachydermatis are responsible for causing dandruff. However, in accordance with the epidemiological data, different Malassezia spp. were found in seborrheic dermatitis patients due to geographical variations (Hedayati et al., 2010). Development of antifungal agents such as the azoles has proven to be effective in removing Malassezia and causing remission of dandruff, but on withdrawal of treatment these microorganisms reappear and dandruff recurs. Limited studies have been conducted till now to find the promising antifungal agent against Malassezia

Correspondence to: Kohinur Begum, E-mail: prof.kohinur@asaub.edu.bd, kohinur025@yahoo.com

DOI: https://doi.org/10.3329/bpj.v22i2.42298 
spp. causing dandruff. Hence, finding the optimum solution in treating dandruff has become a great challenge.

The present study has been conducted to isolate and identify the different Malassezia spp. causing dandruff and to determine the effectiveness of antifungal agents namely, fluconazole, ketoconazole, miconazole and nystatin against these isolates.

\section{Materials and Methods}

Materials: Antifungal drugs (fluconazole, ketoconazole, miconazole and nystatin) were provided by Incepta Pharmaceuticals Ltd. All other chemicals and reagents were analytical grade.

Samples collection: Total 25 samples, 17 males and 8 females of age ranging from 18 to 24 years were selected from students of ASA University Bangladesh. Dandruff flakes were collected using a sterile comb for each sample between the month of December and January, 2019 (Figure 1).

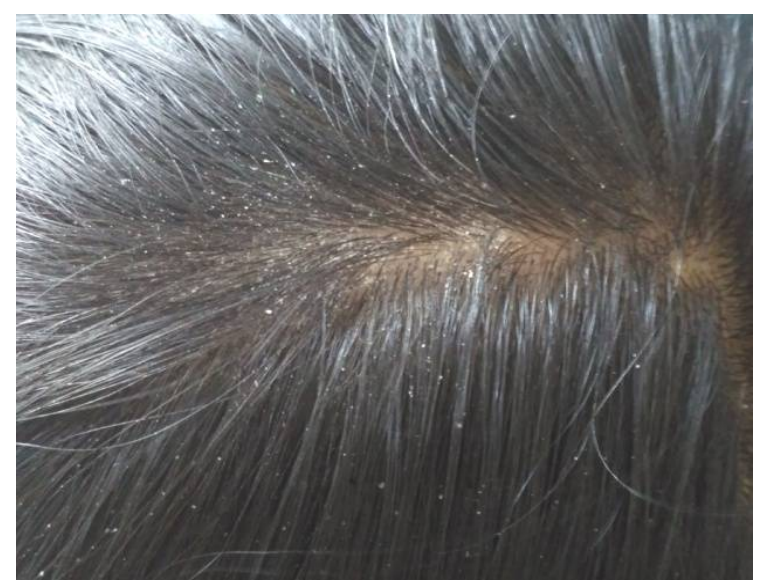

Figure 1. Site of sample collection.

Culture and isolation of colonies: All samples were inoculated in $5 \mathrm{ml}$ Sabouraud dextrose broth and incubated overnight with shaking. Enriched cultures were streaked on Sabouraud dextrose agar (SDA) containing chloramphenicol $(0.05 \%)$ and incubated at $30^{\circ} \mathrm{C}$ for three days. The suspected single colonies were isolated by observing colony morphology and identification was done by further tests as given in a flow chart (Figure 2).

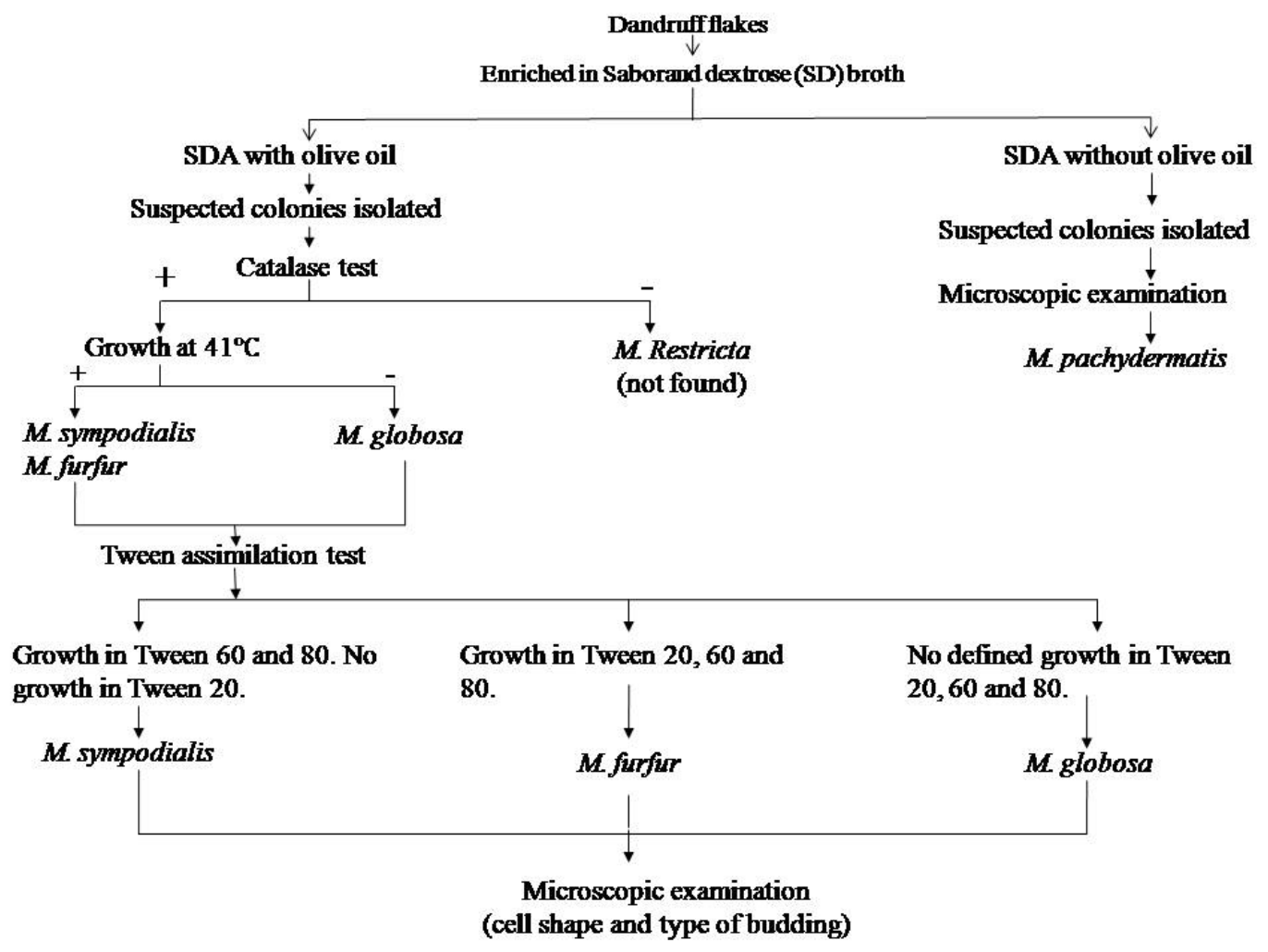

Figure 2. Flowchart for isolation and identification of Malassezia species from dandruff samples. 
Identification of Malassezia species: $M$. pachydermatis, the non-lipid dependent species, favored Sabouraud dextrose agar. Malassezia species which grew on Sabouraud dextrose agar overlaid with olive oil were identified as lipophilic yeasts. The biochemical tests such as catalase test, growth at $41^{\circ} \mathrm{C}$ and tween assimilation test were performed to further differentiate the lipid-dependent species. Microscopic examinations by Gram staining determined the cell shape and type of budding.

Catalase test: The catalase test was performed by using a drop of $3 \%$ hydrogen peroxide placed on glass slide. A sample was transferred to it by a sterile loop and mixed well. The production of gas bubbles indicates catalase positive and the absence of it means catalase negative. Candida albicans was used as positive control. Other than $M$. restricta, all Malassezia species are catalase positive (Gupta et al., 2001; Marishita et al., 2006).

Growth at $41^{\circ} \mathrm{C}$ : The catalase positive isolates were inoculated on SDA plates and incubated at $41^{\circ} \mathrm{C}$. The growth of colonies indicates the positive results.

Tween assimilation test: For each isolate, the ability to utilize Tween was confirmed by Tween assimilation test (Guillot et al., 1996). Suspension of each isolate was made $\left(10^{5}\right.$ cells $\left./ \mathrm{ml}\right)$ in sterilized saline and the inoculum was uniformly spread on SDA plate using sterile cotton swab. Wells were made and $5 \mu \mathrm{l}$ of Tween 20,60 and 80 were added to each well. The plates were incubated at $30^{\circ} \mathrm{C}$ for three days and the growth was observed around the individual well.

Microscopic examination: Microscopic examination was performed for all the isolates to observe the shape of the cells and their type of budding by standard Gram staining procedure.

Antifungal assay: Antifungal effect of the drugs (fluconazole, ketoconazole, miconazole and nystatin) against Malassezia species were performed by well diffusion using SDA agar plates following KirbyBauer method (Bauer et al., 1966). The drug solutions were made using DMSO at concentration of $2 \mathrm{mg} / \mathrm{ml}$. Cell suspension $\left(10^{5}\right.$ cells $\left./ \mathrm{ml}\right)$ was spread uniformly on the agar plate and wells were made. 25 $\mu \mathrm{l}$ of each antifungal agent was added to each well. The SDA plates were incubated in the upright position at $30^{\circ} \mathrm{C}$ for $48 \mathrm{hrs}$. Agar well containing DMSO was used as the negative control. Diameter of the zone of inhibition was recorded in millimeters and average was taken from the duplicate tests.

\section{Results and Discussion}

A total of 35 suspected single colonies from 25 samples were isolated and amongst them 15 isolates were identified as Malassezia spp. (Table 1). Malassezia furfur, M. pachydermatis, $M$. sympodialis and $M$. globosa were identified and results given in table 2 and figure 3. Two of the isolates were identified as $M$. pachydermatis $(13.33 \%)$ and the rest were different lipophilic species, which were M. furfur (66.67\%), M. globosa $(6.67 \%)$ and $M$. sympodialis (13.33\%) as shown in pie chart (Figure 4).

Similar studies were carried out on seborrhoeic dermatitis patients in Iran, India, Korea, Greece, Eastern Europe, Japan and USA. In Iran, M. globosa was the most commonly isolated Malassezia spp. occurring mainly on the scalp and face. However, the second most common species isolated was $M$. furfur followed by M. sympodialis (Hedayati et al., 2010). In Korea and Bosnia and Herzegovina, M. restricta was the most significant species amongst the population suffering from seborrhoeic dermatitis (Lee et al., 2011; Prohic, 2010). In Japan, Greece and USA, M. globosa was mostly found in the people affected by seborrhoeic dermatitis (Gaitanis et al., 2006; Sugita and Velegraki, 2010). In India, two geographically different locations were studied, the North and the South, for the prevalence of the different Malassezia species. M. restricta and $M$. 
globosa were the two most isolated species from dandruff in Northern India, whereas, in the South, $M$. furfur was most prevalent (Rudramurthy et al., 2014). Our findings show that $M$. furfur is the predominant causative agent responsible for dandruff. This result corresponds with Southern India, since Bangladesh share a similar climatic profile due their geographical location.

Table 1. Isolation of Malassezia spp. based on colony morphology using selective media.

\begin{tabular}{cll}
\hline Isolate No. & \multicolumn{1}{c}{ Colony morphology } & \multicolumn{1}{c}{$\begin{array}{l}\text { Suspected } \\
\text { Malassezia spp. }\end{array}$} \\
\hline D1 & Buff colored, smooth, matt surface & M. pachydermatis \\
D2 & Cream colored, smooth, convex, shiny surface & M. pachydermatis \\
D3 & White colored, smooth surface & M. globosa \\
D4 & Cream colored, smooth, shiny surface & M. sympodialis \\
D5 & White colored, finely folded surface, shiny surface & M. sympodialis \\
D6 & Buff colored, smooth, shiny surface & M. furfur \\
D7 & White colored, shiny, finely folded surface & M. furfur \\
D8 & White colored, shiny and smooth surface & M. furfur \\
D9 & Cream colored, convex, deeply folded surface & M. furfur \\
D10 & White colored, convex, shiny, finely folded surface & M. furfur \\
D11 & Buff colored, convex, shiny smooth surface & M. furfur \\
D12 & Cream colored, convex, shiny smooth surface & M.furfur \\
D13 & Cream to buff colored, shiny smooth surface & M. furfur \\
D14 & Cream colored, convex, shiny smooth surface & M.furfur \\
D15 & Cream colored, convex, shiny smooth surface & M.furfur \\
\hline
\end{tabular}

Table 2. Identification of Malassezia spp. based on the biochemical tests and microscopic examination.

\begin{tabular}{|c|c|c|c|c|c|c|c|c|c|}
\hline \multirow{2}{*}{$\begin{array}{l}\text { Isolate } \\
\text { No. }\end{array}$} & \multirow{2}{*}{$\begin{array}{l}\text { Lipid } \\
\text { depen- } \\
\text { dence }\end{array}$} & \multirow{2}{*}{$\begin{array}{c}\text { Catalase } \\
\text { test }\end{array}$} & \multirow{2}{*}{$\begin{array}{l}\text { Growth } \\
\left(41^{\circ} \mathrm{C}\right)\end{array}$} & \multicolumn{3}{|c|}{ Tween Test } & \multicolumn{2}{|c|}{ Microscopic examination } & \multirow[t]{2}{*}{ Species identified } \\
\hline & & & & $\mathrm{T} 20$ & T60 & $\mathrm{T} 80$ & Cell shape & Budding type & \\
\hline D1 & - & N/A & N/A & N/A & N/A & N/A & Spherical & Narrow based & M. pachydermatis \\
\hline D2 & - & N/A & N/A & N/A & N/A & N/A & Oval & Narrow based & M. pachydermatis \\
\hline D3 & + & + & - & - & - & - & Spherical & Broad based & M. globosa \\
\hline D4 & + & + & + & + & + & + & Oval & Sympodial & M. sympodialis \\
\hline D5 & + & + & + & + & + & + & Oval & Sympodial & M. sympodialis \\
\hline D6 & + & + & + & + & + & + & Oval & Broad based & M. furfur \\
\hline D7 & + & + & + & + & + & + & Oval & Broad based & M. furfur \\
\hline D8 & + & + & + & + & + & + & Oval & Broad based & M. furfur \\
\hline D9 & + & + & + & + & + & + & Oval & Broad based & M. furfur \\
\hline D10 & + & + & + & + & + & + & Oval & Broad based & M. furfur \\
\hline D11 & + & + & + & + & + & + & Cylindrical & Broad based & M. furfur \\
\hline D12 & + & + & + & + & + & + & Oval & Broad based & M. furfur \\
\hline D13 & + & + & + & + & + & + & Oval & Broad based & M. furfur \\
\hline D14 & + & + & + & + & + & + & Oval & Broad based & M. furfur \\
\hline D15 & + & + & + & + & + & + & Oval & Broad based & M. furfur \\
\hline
\end{tabular}

$+=$ Positive result, $-=$ Negative result, N/A = Not applicable 


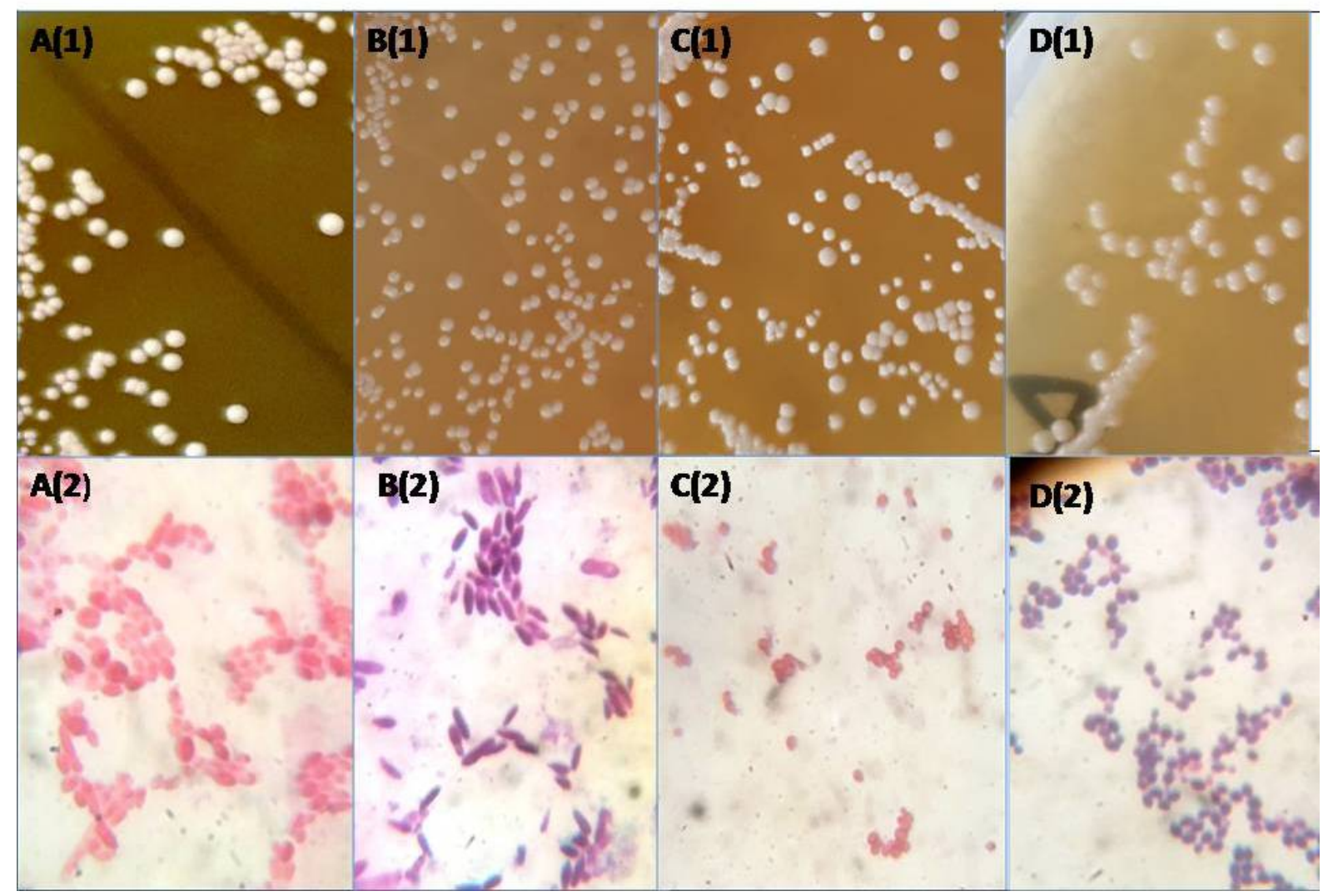

Figure 3. Image showing colony morphology on SDA plates (1) and microscopic examination by Gram staining (2): (A) $M$. pachydermatis (B) M. furfur (C) M. globosa (D) M. sympodialis.

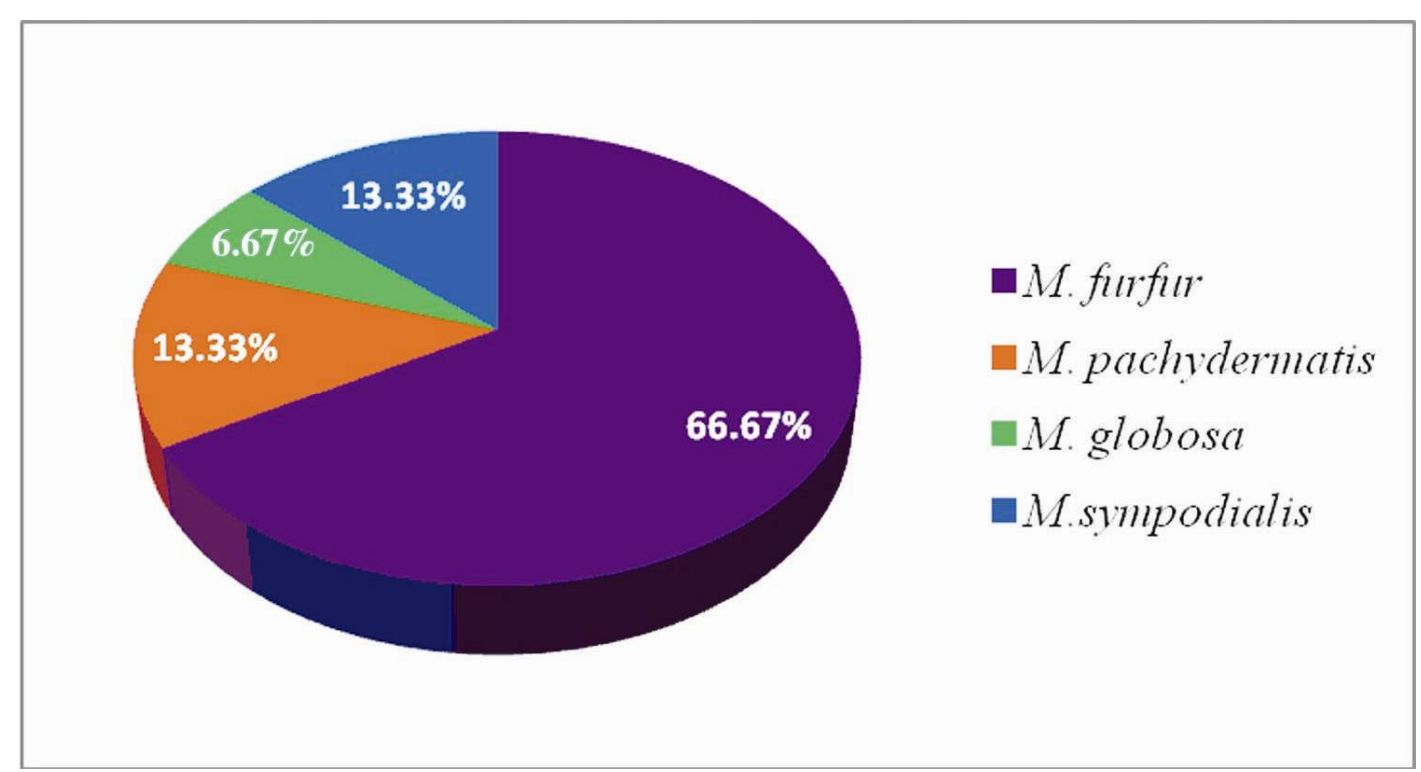

Figure 4. Prevalence of different Malassezia species from dandruff samples. 
Table 3. Results of antifungal assay of Malassezia species.

\begin{tabular}{lcccc}
\hline Isolate No. & \multicolumn{4}{c}{ Zone of Inhibition $(\mathrm{mm})$} \\
\cline { 2 - 5 } & $\begin{array}{c}\text { Fluconazole } \\
(50 \mu \mathrm{g})\end{array}$ & $\begin{array}{c}\text { Miconazole } \\
(50 \mu \mathrm{g})\end{array}$ & $\begin{array}{c}\text { Ketoconazole } \\
(50 \mu \mathrm{g})\end{array}$ & $\begin{array}{c}\text { Nystatin } \\
(50 \mu \mathrm{g})\end{array}$ \\
\hline D1 & 30 & 28 & 34 & 36 \\
D2 & 36 & 19 & 35 & 31 \\
D3 & 40 & 14 & 30 & 20 \\
D4 & 20 & 20 & 25 & 25 \\
D5 & 30 & 20 & 30 & 22 \\
D6 & 22 & 13 & 22 & 14 \\
D7 & 40 & 30 & 30 & 40 \\
D8 & 35 & 12 & 30 & 30 \\
D9 & 36 & 15 & 25 & 20 \\
D10 & 18 & 17 & 18 & 20 \\
D11 & 34 & 14 & 30 & 24 \\
D12 & 35 & 12 & 30 & 22 \\
D13 & 40 & 30 & 35 & 23 \\
D14 & 40 & 15 & 38 & 20 \\
D15 & 40 & 15 & 36 & 22 \\
\hline
\end{tabular}

Results of antifungal activities have shown sensitivity for all the strains to varying degrees (Table 3 and Figure 5). Fluconazole and ketoconazole were the most effective antifungal agents whereas miconazole, an imidazole, showed the least effectiveness. Previous studies also showed M. furfur, M. sympodialis, M. pachydermatis and M. globosa to be susceptible to the azoles, especially ketoconazole (Miranda et al., 2007; Sugita et al., 2005). Even though nystatin is not an azole, it showed effectiveness comparable to fluconazole and ketoconazole against few strains.

The established antidandruff treatment frequently prescribed by dermatologists in Bangladesh is $2 \%$ ketoconazole, in the form of shampoo and foam. However, our findings show that fluconazole and ketoconazole are comparable in inhibiting Malassezia spp. Currently, oral formulations of fluconazole are mostly available for local and systemic fungal infections. However, oral usage of fluconazole is inadvisable due to its multiple side effects mainly those affecting the liver and the kidney (Basha et al., 2011). Formulating fluconazole into a topical

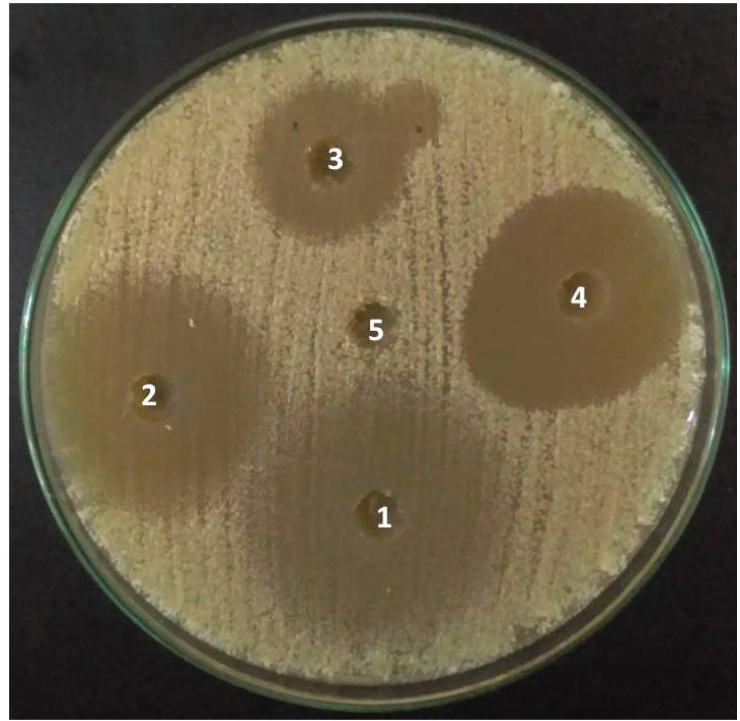

Figure 5. Zone of inhibition of isolate D2 using (1) fluconazole, (2) ketoconazole, (3) miconazole, (4) nystatin and (5) DMSO.

preparation can reduce these side effects together with increasing treatment efficacy and patient compliance. As topical formulations of fluconazole are currently not available for dandruff treatment, 
extensive research can be conducted to develop an optimum formulation in treating dandruff.

\section{Conclusion}

In this study, M. furfur, M. pachydermatis, $M$. sympodialis and $M$. globosa were found from dandruff samples and $M$. furfur was the most predominant species. All strains were sensitive to fluconazole, ketoconazole, miconazole and nystatin. However, ketoconazole and fluconazole were most effective agents. From this preliminary study it can be concluded that an extensive research is required involving mass population and the development of an effective topical formulation for combating dandruff.

\section{References}

Basha, B.N., Prakasam, K. and Goli, D. 2011. Formulation and evaluation of gel containing fluconazoleantifungal agent. Int. J. Drug Dev. Res. 3, 109-128.

Bauer, A.W., Kirby, W.M.M., Sherris, J.C. and Turck, M. 1966. Antibiotic susceptibility testing by a standardized single disc method. Am. J. Clin. Pathol. 36, 493-496.

Elewski, B.E., 2005. Clinical diagnosis of common scalp disorders. J. Investig. Dermatol. Symp. Proc. 10, 190193.

Gaitanis, G., Velegraki, A., Alexopoulos, E.C., Chasapi, V., Tsigonia, A. and Katsambas, A. 2006. Distribution of Malassezia species in pityriasis versicolor and seborrhoeic dermatitis in Greece. Typing of the major pityriasis versicolor isolate $M$. globosa. Br. J. Dermatol. 154, 854-859.

Guillot, J., Gueho, E., Lesourd, M., Midgley, G., Chevrier, G. and Dupont, B. 1996. Identification of Malassezia species: a practical approach. J. Med. Mycol. 6, 103110.

Gupta, A.K., Kohli, Y, Faergemann, J. and Summerbell, R.C. 2001. Epidemiology of Malassezia yeasts associated with pityriasisversicolor in Ontario, Canada. Med. Mycol. 39, 199-206.
Hay, R.J. 2011. Malassezia, dandruff and seborrhoeic dermatitis: an overview., Br. J. Dermatol. 165, 2-8.

Hay, R.J. and Graham Brown, R.A.C. 1997. Dandruff and seborrhoeic dermatitis: causes and management. Clin Exp Dermatol. 22, 2-6.

Hedayati, M.T., Hajheydari, Z., Hajjar, F., Ehsani, A., Shokohi, T. and Mohammadpour, R., 2010. Identification of Malassezia species isolated from Iranian seborrhoeic dermatitis patients. Eur. Rev. Med. Pharmacol. Sci. 14, 63-68.

Lee, Y.W., Byun, H.J., Kim, B.J., Kim, D.H., Lim, Y.Y., Lee, J.W., Kim, M.N., Kim, D., Chun, Y.J., Mun, S.K. and Kim, C.W. 2011. Distribution of Malassezia species on the scalp in Korean seborrheic dermatitis patients. Ann. Dermatol. 23, 156-161.

Miranda, K.C., de Araujo, C.R., Costa, C.R., Passos, X.S., Fernandes, O.D.F.L. and Silva, M.D.R.R., 2007. Antifungal activities of azole agents against the Malassezia species. Int. J. Antimicrob. Agents 29, 281284.

Morishita, N., Sei, Y. and Sugita, T., 2006. Molecular analysis of Malassezi a microflora from patients with pityriasis versicolor. Mycopathologia 161, 61-65.

Prohic, A. 2010. Distribution of Malassezia species in seborrhoeic dermatitis: correlation with patients' cellular immune status. Mycoses 53, 344-349.

Ranganathan, S. and Mukhopadhyay, T., 2010. Dandruff: The most commercially exploited skin disease. Indian J. Dermatol. 55, 130-134.

Rudramurthy, S.M., Honnavar, P., Dogra, S., Yegneswaran, P.P., Handa, S. and Chakrabarti, A.2014. Association of Malassezia species with dandruff. Indian J. Med. Res. 139, 431-437.

Sugita, T., Tajima, M., Ito, T., Saito, M., Tsuboi, R. and Nishikawa, A. 2005. Antifungal activities of tacrolimus and azole agents against the eleven currently accepted Malassezia species. J. Clin. Microbiol. 43, 2824-2829.

Sugita, T. and Velegraki, A. 2010. Epidemiology of Malassezia-related skin diseases. In: Malassezia and the skin (Boekhout, T, Guého-Kellermann, E, Mayser, P, Velegraki, A, eds). Springer-Verlag, Berlin, Heidelberg, pp. 65-120. 